\title{
ESTIMATION OF BASE ISOLATED STRUCTURE RESPONSES
}

\author{
D. M. Lee* and I. C. Medland**
}

\section{ABSTRACT}

The dynamic responses of a set of elastic six storey shear structures mounted on a bilinear hysteretic Base Isolation (B.I.) System and forced by a wide range of different 'types' and 'strengths' of real and simulated earthquakes, are studied. The responses of the same set of structures, without the Base Isolation System, to the same range of earthquakes are also computed for comparative purposes.

It is found that for the B.I. system investigated, not only are the maximum shear forces in an isolated structure reduced to, on average, 0.2 of their values without B.I., but also that the maximum shear responses of isolated structures can be closely estimated from a wide variety of different parameters, selected from ground motion and elastic response spectrum data of the forcing earthquakes. Ninety-five percent confidence intervals are determined for the linear least squares regression relations between structure responses and earthquake parameters.

For the isolation system considered the maximum displacement across the isolation system during an earthquake is shown to be very closely correlated with the maximum structure shear force.

\section{INTRODUCTION}

The Base Isolation (B.I.) System ${ }^{(1)}$ is a recently developed, practical and convenient form of 'soft first storey' for shielding a structure from earthquake attack. The structure is supported at its base-foundation interface on horizontally flexible but vertically rigid laminated rubber pads $(2)$. Hysteretic dampers $(3,4,5)$ connected between the structure base and foundation provide an effectively rigid connection for strong wind loading or mild earthquake motions but with the onset of strong earthquake motions these dampers yield, reducing the stiffness of the structure base-foundation connection and providing hysteretic damping on the displacements that occur there. It has been shown that such a system dramatically lowers the shear responses expected in single degree of freedom $(6,7,8)$ and multi storey $(1,9,10,11)$ structures subjected to moderate sized earthquakes. However in all of the above studies a single earthquake, a statistical class of earthquake or a single scaled earthquake accelerogram was used to excite the given isolated structures and hence little information was obtained on the effect of different types of earthquake motions on the responses of isolated structures. Obviously a 'large' earthquake will cause a higher shear response in an isolated structure than will a 'small' earthquake but it remains to be determined which characteristics or parameters of an earthquake are causative in determining these responses.

In an analytical and experimental

* Graduate Student, Department of Theoretical and Applied Mechanics, University of Auckland. (Now Post Doctoral Fellow in Earthquake Engineering, California Institute of Technology.)

* * Senior Lecturer in Theoretical and Applied Mechanics, University of Auckland. investigation of a 'Soft Storey Isolation System' Kelly et.al. (12) suggested a design procedure utilising effective periods and damping factors of the isolated structure and the $30,35,40$ and $45 \%$ damped single d.o.f. elastic response spectra of the forcing earthquake in an iterative, mode superposition approach. While this procedure gave reasonable estimates of the expected maximum structure shears it did not give good estimates of the maximum base displacement as it could not take nonlinear base shifting into account. The procedure also has the disadvantage that effective periods and damping factors of the structure must be calculated and that highly damped response spectra, not generally available in published form, must be used in evaluating modal contributions. Furthermore the procedure is iterative.

In this work a simplified technique is developed for estimating the maximum responses of a given multi-storey structure, mounted on a B.I. system, to excitation by a given earthquake. The technique consists of correlating observed structure responses with easily selected ground motion and single d.o.f. elastic response spectra (5, 10 and $20 \%$ damped) of the forcing earthquakes. The responses of unisolated structures are considered for comparative purposes.

\section{STRUCTURE MODELS AND PARAMETERS USED}

The structure models used in this investigation are six storey lumped parameter shear structures with viscous damping and B.I. system properties as defined in Section 2.1 of reference 1 . Structure 'period' notation of $\mathrm{T}_{i}$ (UI). $\mathrm{T}_{i}$ (IUY), and $\mathrm{T}_{i}$ (IY)' denoting the period of 'mode' $i$ for the unisolated structure, the isolatedunyielded structure and the isolated-yielded 
structure (using only the elastic components of the yielded B.I. system) respectively, is again used here. The 'Bulge Defining Parameter'(1), $\mathrm{B}_{\mathrm{D}}$ ' is used to indicate the size of the shear forces in the upper levels of a structure relative to that at the base while the maximum shear in a structure divided by its total above base weight is again denoted by $S$, and normally, but not always, occurs at the structure base.

Three structures are considered, having $\mathrm{T}_{I}(\mathrm{UI})=0.3,0.6$ and 0.9 seconds respectively but because the effect of different amounts of viscous damping, numbers of storeys and types of structure (different relationships between modal periods) have been shown $(13)$ to have only second order effects on the responses of isolated structures the results of this paper are expected to be qualitatively applicable to a wider range of structures than that investigated here.

\section{EARTHQUAKE RECORDS USED}

Table 1 lists the earthquake records used to investigate the effect of different earthquakes on the responses of isolated structures. Eleven actual and eight simulated earthquake records were selected, so as to provide a representative range of the different types and strengths of earthquake that occur. The actual earthquake records were mostly from sites having 19 to 80 metres of stiff soil deposits but two records were included from sites on solid rock (Pacoima Dam) and two from sites with soft clay/sand deposits (Niigata). The Pacioma Dam accelerograms were recorded on a ridge and it is thought that much of the character of these accelerograms is a result of partial lateral resonance of this ridge, which would account for the very high accelerations and the relative lack of long period motions in these records. The Niigata accelerograms were however recorded on level silty soil in which extensive liquefaction occurred near the recording site and hence these records have low accelerations and dominant long period motions. Thus the Pacioma Dam and Niigata accelerograms represent two extremes of possible types of earthquakes and, as such, are particularly useful in exploring the versatility and usefulness of base isolation in protecting a structure from a given earthquake. The simulated earthquakes derived by Jennings, Housner and Tsai(14) model four types of strong earthquake motions as indicated in Table 1 .

For all the 19 earthquake records, the entire accelerogram (as obtained from the relevant source $(14,15,16)$ was utilised in order to be certain of including the effect, on the overall structure response, of long period motions which frequently occur in the latter portion of an accelerogram and in order to obtain accurate data on the residual effect of the isolation system following an earthquake. Elastic, single degree of freedom, velocity and acceleration response spectra $(5,10$ and $20 \%$ damped) were derived for the earthquake records of Table liby the 'exact' method of Nigam and Jennings (17) and 5,10 and $20 \%$ damped Spectral Intensities (the area between 0.1 and 2.5 seconds under the appropriately damped relative velocity response spectrum) also evaluated for use as possible earthquake parameters.

\section{CORRELATION OF STRUCTURE RESPONSES WITH EARTHQUAKE PARAMETERS}

Isolated and unisolated structures as defined in section 2 were excited by the records of each of the 19 earthquakes of Table $I$ and their maximum responses recorded. The degree of correlation between the actual structure responses and the response spectrum data was quantified by fitting a least squares straight line to these sets of points and then evaluating the adjusted coefficient of determination, $\bar{R}^{2}$, of the fitted line. The statistic $\bar{R}^{2}$ determines the degree to which the independent variable (s) (the response spectrum data) explain(s) the variation in the dependent variable (the actual structure response parameter) and takes values from zero (no correlation between the dependent and independent variables) to 1.0 (a direct linear relationship between the dependent and independent variables): However because $\mathrm{R}^{2}$ has been adjusted for the number of degrees of freedom, it can in fact take on small negative values if the correlation between the variables is extremely poor. Ninety-five percent confidence intervals on the data points are also constructed around the fitted least square lines.

The responses of unisolated structures of $\mathrm{T}_{7}$ (uT $=0.3,0.6$ and 0.9 seconds are plotted by the symbols $\Delta, \nabla, \square$ respectively whereas the responses of these same structures when isolated are plotted by the symbols $x$, and + . On these plots solid lines are used to represent least squares fitted lines while dashed lines are used to represent 95\% confidence intervals on the data points.

Now quantities such as the maximum ground acceleration or the $20 \%$ damped Housner Spectral Intensity are often used as a qualitative gauge of the strength of an earthquake. Such 'simple' parameters however take no account of the dynamic chäracteristics of the structure whose responses are to be correlated with the forcing earthquake. Alternative parameters can be 'selected' from the response spectra of the forcing earthquake at hatural periods' of the structure being excited. Both types of parameter are considered and are dealt with in turn below.

\subsection{Simple Parameters}

The responses of isolated (and for comparative purposes, unisolated structures to the set of 19 earthquakes were related to the maximum ground velocities and accelerations (M.G.V., M.G.A.), the 20, 10 and $5 \%$ damped Housner Spectral Intensities (H.S.I. $20,10,5)$ and the maximum values of the 20 , 10 and $5 \frac{6}{6}$ damped acceleration and velocity response spectra (M.S.A. $20,10,5$, M.S.V. 20, 10,5). dimensionalised maximum shear response, S, and each of the eleven simple earthquake parameters is described by the fitted straight line,

$S^{e}=a+b$ (E.Q. Parameter)

where $S^{e}$ is the least squares estimate of $S$, while the degree of correlation between $S$ and each earthquake parameter is quantified by $\overline{\mathrm{R}}^{2}$. Values of $\mathrm{a}, \mathrm{b}$ and $\overline{\mathrm{R}}^{2}$, for both isolated and unisolated structures, are listed in Table 2. 


\section{Table 2.}

A number of points can be made concerning

(i) For isolated structures there is a much closer correlation between $S$ and velocity parameters than between $S$ and acceleration parameters. The converse is true for unisolated structures. Such relationships with the maximum values of the response spectra can be understood when it is realised that the unisolated structures have periods in the region 0.0 to 1.0 second, which is the period region in which acceleration response spectra typically have their maximum values, while the isolated structures have their fundamental 'periods' in the region 1 to 2 seconds and this is the period region in which velocity response spectra maxima typically occur.

(ii) The fundamental periods of the unisolated structures may vary from 0.3 to 0.9 seconds while the pseudo fundamental periods of the isolated-yielded structures vary from 2.18 to 2.31 seconds. Now the period range of zero to one second is the region in which both the acceleration and velocity response spectra vary most rapidly and hence a set of structures with a wide range of periods in this region (i.e. the unisolated structures) will display greater variation in response than a set of structures having not only a narrower range of periods but having these periods in the region above one second where the spectra are more constant.

(iii) The 20\% damped Housner Spectral Intensity (H.S.I.20\%) is often used as a measure of the energy that a given earthquake can transmit into a structure. It is therefore of interest to note that this parameter gives a quite reasonable $\left(\overline{\mathrm{R}}^{2}=0.814\right)$ description of the maximum shear expected in a base isolated structure but gives a poor description $\left(\overline{\mathrm{R}}^{2}=.488\right)$ of that expected in an unisolated structure. In Figure 1 the actual values of $\mathrm{S}$ for both isolated and unisolated structures subjected to a given earthquake are plotted against the H.S.I. $20 \%$ for that earthquake. (The solid lines are the least squares fitted lines (from Table 2) while the dashed lines are $95 \%$ confidence intervals on the data points, as noted earlier.) The confidence intervals around the fitted line of Figure 1 are actually hyperbolic curves but because of their extreme flatness they can be conservatively approximated by straight lines. For the isolated case such lines can be derived by adding and subtracting 0.08 from the least squares line. Such 'approximate' confidence intervals are referred to again later in this work.

(iv) The 'best' simple earthquake parameter for describing the response of isolated structures is the maximum value of the $20 \%$ damped velocity response spectrum, M.S.V.20\%, which gives an $\bar{R}^{2}$ value of 0.907 . In comparison the best $\mathrm{R}^{2}$ for the unisolated structures is 0.506 for the maxima of the 10 and $20 \%$ damped acceleration response spectra.

The maximum displacement across the isolation system, $d_{B}$, is closely aligned with $S$ and the least squares regression line of $d_{B}$ on $S$, for each of the isolated structures $\left(\mathrm{T}_{1 \text { (UI) }}=0.3,0.6\right.$ and 0.9 seconds) forced by each of the 19 earthquake records has the equation

$d_{B}(\mathrm{~cm})=-4.6+114.7 \mathrm{~s}$

and an adjusted coefficient of determination of $\bar{R}^{2}=0.9864$.

The distribution of the maximum shear up the structure, as given by $B_{D}$, displayed very little correlation with any of the simple earthquake parameters considered, the maximum value of $\overrightarrow{\mathrm{R}}^{2}$ for both isolated and unisolated structures being only 0.17 . It was noted, however, that for isolated structures $\mathrm{B}_{\mathrm{D}}$ tended to increase as $\mathrm{T}_{1}$ (UI) increased, whereas $B_{D}$ for unisolated structures was relatively unaffected by $\mathrm{T}_{1}$ (UI) - (For structures of $\mathrm{T} I$ (UI) $=0.3$, 0.6 and 0.9 seconds, the mean values of $\mathrm{B}_{\mathrm{D}}$ were respectively $0.09,0.28$ and 0.39 for isolated structures, but $0.22,0.33$ and 0.34 for unisolated structures.) Accordingly the values of $B_{D}$ for structures of $\mathrm{T}_{1 \text { (UI) }}=0.3,0.6$ and 0.9 seconds were regressed separately against each of the three better earthquake parameters in turn (i.e. the $20 \%$ damped H.S.I., M.S.V. and M.S.A.). Some slight correlation $\left(\bar{R}^{2}=.33\right.$, $.42, .26$ for $\mathrm{T} I$ (UI) $=0.3,0.6,0.9$ seconds) was then found to exist between $\mathrm{B}_{\mathrm{D}}$ for isolated structures and the M.S.V. $20 \%$ of the forcing earthquake, with $\mathrm{B}_{D}$ decreasing as the earthquake strength (as indicated by the M.S.V.20\%) increased. For the unisolated structures $B_{D}$ still displayed almost zero correlation with any of the earthquake parameters.

Because of the hysteretic nature of the B.I. system the structure will generally come to rest slightly offset from its original position following an earthquake. The residual plastic offset, $\delta_{\mathrm{PL}}$, of each of the isolated structures following each of the 19 earthquakes was found to display no correlation at all with any of the earthquake parameters investigated, both with and without segregation of data according to $\mathrm{T}(\mathrm{UI})$.

It is worthy of note, however, that the largest values of $\delta_{\mathrm{PL}}(38 \mathrm{~mm})$ occurred for structures forced by the Niigata (N.S. and E.W.) motions, which have high energy, long period motions. Base isolation is unsuited to such motions and the Niigata earthquake can in fact produce shears in an isolated structure which are higher than those which would arise if the same structure were unisolated. Thus base isolation should not be used as an earthquake protection mechanism for structures located on very deep silty soils where there is the possibility of dominant long period motions. (For such subsoil conditions the major problem for the design may be soil liquefaction and gross ground deformation, not structural vibrations). Neglecting the Niigata earthquake the mean value and maximum value of $\delta_{\mathrm{PL}}$ was 3.5 and $17 \mathrm{~mm}$ respectively.

\subsection{Selected Parameters}

The earthquake parameters $\mathrm{P}_{1}$ and $\mathrm{P}_{2}$ selected for use in predicting $S$ are the ordinate values of earthquake response spectra at approximations to the first and second mode 'periods' of the structure being considered. These parameters were chosen because the maximum shear in a structure is 
largely dependent on the degree of response of the first and second modes of vibration to the earthquake forcing. The values. of $\mathrm{P}_{1}$ and $\mathrm{P}_{2}$ vary not only from one earthquake to another but also from one structure to another for the same earthquake, because of different structure periods. A further degree of variability is added with isolated structures where either the isolated-unyielded or the isolated-yielded 'periods' can be used. Furthermore, the ordinate values can be obtained from either of the 5,10 or 20 percent damped relative velocity or absolute acceleration response spectra for each earthquake. There are therefore 18 different pairs of parameters against which isolated structure responses can be compared.

Because the response spectra were evaluated at period intervals of 0.05 seconds the response spectra values are taken at the nearest evaluated oscillator period to the structure period of concern. Although it would have been a simple matter to evaluate the parameters at the exact period values, it was felt preferable to use data of a type which is widely available in published form so that the plots of structure response versus response spectrum parameters could be used with confidence by others having access to only such published data. Table 3 gives the actual first and second mode periods of the structures considered, together with the approximations at which the response spectrum data was selected.

The effectiveness of different parameters in describing structure response is (as in the previous sub-section) quantified using the adjusted coefficient of determination $\bar{R}^{2}$. Where two parameters are used in an attempt to better explain the structure's response, the parameters are fitted together first in a multiple regression, and then individually.

The results of this investigation are given in Table 4 where the values of $\bar{R}^{2}$ for the different regression fits are summarised. It can be seen that for unisolated structures the best fit between $S$ and the earthquake parameters is provided by parameters from the 5\% damped acceleration response spectra, which is as expected since these structures have 5\% viscous damping in each mode and $S$ is an acceleration dependent quantity in an elastic system. The value of $\mathrm{R}^{2}$ is very nearly the same $(. \dot{4} 869)$ for the fit of $\mathrm{S}$ against both parameters 1 and 2 together and parameter $I$ alone because the contribution of $\mathrm{P}_{2}$ is very small $\left(\overline{\mathrm{R}}^{2}=.2506\right)$.

For base isolated structures the correlation between $S$ and the earthquake parameters is better for the parameters derived at the isolated-yielded pseudo periods than at the isolated-unyielded periods. Furthermore the correlation is better when higher levels of damping of the spectral data are used and is also generally better when using the velocity rather than the acceleration spectral data. Almost equally good correlation is however obtained between $S$ and earthquake data (using the isolated-yielded pseudo periods) from the 20\% damped acceleration and the 10\% and $20 \%$ damped velocity response spectra. The best correlation (of $\overline{\mathrm{R}}^{2}=.9458$ ) compares very well with that for the unisolated structures, especially when it is considered that one is correlating the response of an inelastic structure with elastic response spectrum data at inexact oscillator periods. It can also be seen from Table 4 that $\mathrm{P}_{2}$ explains very little of the variation in $S$ and hence the correlation between $S$ and $P_{1}$ alone is, in most cases, almost as good as that between $S$ and $P_{1}$ and $\mathrm{P}_{2}$ together.

In Figure 2 a plot of $S$ for unisolated structures versus $\mathrm{P}_{1}$ (using the unisolated periods and the 5\% damped acceleration spectra) is super-imposed with a plot of $S$ for isolated structures versus $\mathrm{P}_{1}$ (using the isolated-yielded pseudo periods and the 10\% damped velocity spectra) for comparative purposes. The abcissa values for the unisolated structures have been multiplied by a factor of 0.08 before being plotted. Although a given structure will of course not have the same abcissa value when both isolated and unisolated, thus disallowing direct comparisons of $\mathrm{S}$, the overall interpretation that base isolated structures have not only dramatically lowered but also accurately predictable shear responses is nevertheless correct.

Table 5 summarises the better linear least squares regression fits of $S$ against $\mathrm{P}_{1}$ alone. (The fit of $\mathrm{S}$ to the 5\% damped acceleration spectra is given because studies on the dependence of 5\% damped acceleration response spectra on site conditions have already been carried out. (18))

It can be seen from Tables 4 and 5 that the responses of isolated structures can be accurately correlated with a wider array of parameters than can those of unisolated structures. Although the maximum value of $\mathrm{R}^{2}$ is lower for the isolated than unisolated structures, the actual widths of the approximate 95\% confidence intervals around the fitted lines are smaller, because of the much lower values of $\mathrm{S}$.

The maximum base displacement, $d_{B}$, was shown in the previous sub-section to be closely correlated with the maximum nondimensionalised shear, $S$, thus removing the necessity to relate $d_{B}$ directly to earthquake parameters. However, although Equation 2 is sufficient to find $d_{B}$ if $S$ itself can be predicted, the errors in estimating $d_{B}$ from $S$ are compounded by those in estimating $S$ from the earthquake parameter. A plot of $d_{B}$ versus the $10 \%$ damped spectral velocity at $\mathrm{T}_{1}$ (IY) was therefore drawn and the associated least squares regression line,

$$
\mathrm{d}_{\mathrm{B}}=-\frac{34.1+270.7 \times \mathrm{x} \text { (Spectral Velocity }}{\left.10 \% \mathrm{a} \mathrm{T}_{I(\mathrm{IY})}(\mathrm{mm})\right)}
$$

had an $\overline{\mathrm{R}}^{2}$ of 0.9403 . Ninety-five percent confidence intervals on this line are approximately and conservatively given by adding and subtracting $52 \mathrm{~mm}$ from the above regression line.

Now as the amplitude of second mode effects increases relative to the amplitude of first mode effects, the value of $B_{D}$ for a structure increases. (1) Hence a quantity likely to display some correlation with the value of $\mathrm{B}_{\mathrm{D}}$ that occurs in a given structure forced by a given earthquake is the ratio $\mathrm{P}_{2} / \mathrm{P}_{3}$. It was noted in the previous subsection however that for isolated structures 
the value of $B_{D}$ tended to decrease as the earthquake strength increased. Thus $P_{1}$ alone could also be used as a descriptor of $\mathrm{B}_{\mathrm{D}}$. Both $\mathrm{P}_{2} / \mathrm{P}_{1}$ and $\mathrm{P}_{1}$ were used as parameters in correlating the shear distribution (as given by $\mathrm{B}_{\mathrm{D}}$ ) of isolated and, for comparative purposes, unisolated structures with the properties of the forcing earthquakes. As before, 5, 10 and 20 percent damped acceleration and velocity spectra were used and data for the three structures $\left(\mathrm{T}_{\text {(UI) }}=0.3,0.6\right.$ and 0.9 seconds) was selected from the response spectra at the first and second mode periods of the unisolated structures, for the unisolated structures, and at both the isolated-unyielded and isolated-yielded 'periods' of the isolated structures. The correlation of $\mathrm{BD}$ with this data is summarised in terms of $\overline{\mathrm{R}}^{2}$ in Table 6 , from which the following points may be made.

(i) For isolated structures of $\mathrm{T}_{I}(\mathrm{UI})=$ 0.3 seconds, a good correlation

$\left(\dot{\mathrm{R}}^{2}=.78\right)$ exists between $\mathrm{B}_{\mathrm{D}}$ and certain response parameters, which is in direct contrast to the situation with unisolated structures where the quantities $\mathrm{P}_{2} / \mathrm{P}_{1}$ and $\mathrm{P}_{1}$ display no correlation at all with $\mathrm{B}_{\mathrm{D}}$. This is a particularly interesting result as it is the low period structures on which base isolation has the most beneficial effect in reducing maximum shear.

(ii) For isolated structures, both $\mathrm{P}_{2} / \mathrm{P}_{1}$ and $\mathrm{P}_{1}$ display significant correlation with $\mathrm{B}_{\mathrm{D}}$ and hence the use of both parameters together in a multiple regression generally provides an improvement in $\overline{\mathrm{R}}^{2}$ over that possible using either parameter alone.

(This was not the case for $\mathrm{S}$ where $\mathrm{P}_{1}$ alone was the best descriptor.)

(iii) For isolated structures of $\mathrm{T}_{1 \text { (UI) }}=$ 0.6 and 0.9 seconds, the data from the isolated-yielded periods generally provide a better correlation with $\mathrm{B}_{\mathrm{D}}$ than does data from the isolated-unyielded periods. The converse is true for structures of $\mathrm{T}_{1}$ (UI) $=0.3$ seconds.

(iv) The correlation of $\mathrm{B}_{\mathrm{D}}$ with $\mathrm{P}_{2} / \mathrm{P}_{1}$ and $P_{1}$ (separately and together) is closer when the parameters are derived from the acceleration rather than the velocity spectra and in general also improves as the damping of the spectra increases.

(v) The best single descriptor of $\mathrm{B}_{\mathrm{D}}$ for isolated structures is the parameter $\mathrm{P}_{2} / \mathrm{P}_{1}$ evaluated from the $20 \%$ damped acceleration spectra at the isolated-yielded structure periods. $\mathrm{B}_{\mathrm{D}}$ is plotted against this parameter in Figure 3. For comparison, Figure 4 shows the plot of $B_{D}$ for the unisolated structures against $\mathrm{P}_{2} / \mathrm{P}_{1}$, evaluated from the $5 \%$ damped acceleration spectra using the unisolated structure periods. For the unisolated structures of $\mathrm{T}_{I}$ (UI) $=0.3$ seconds, there is no statistical significance in the fitted regression line as $\overline{\mathrm{R}}^{2}$ was -0.0715 . The mean value of $\mathrm{B}_{\mathrm{D}}=0.2179$ with confidence intervals of plus and minus two standard deviations was therefore drawn instead. Comparing Figures 3 and 4 it can be seen that for structures of $\mathrm{T}_{1}$ (UI) $=0.6$ and 0.9 seconds, base isolation has no real effect in reducing $\mathrm{B}_{\mathrm{D}}$. There is some lowering of $\mathrm{B}_{\mathrm{D}}$ below that possible for unisolated structures, if isolated structures of $\mathrm{T}_{I}(\mathrm{UI})=0.6$ seconds are attacked by earthquakes of low $\mathrm{P}_{2} / \mathrm{P}_{1}$. It is however the low period structures $\left(T_{I}(U I)=0.3\right.$ seconds) that benefit most, as regards $\mathrm{B}_{\mathrm{D}}$, from base isolation as the fitted regression line for isolated structures is below the mean line for the unisolated structures over the whole set of earthquakes considered.

If slightly greater determination is required in predicting $B_{D}$ (for isolated structures) from earthquake data, the full two parameter regression model must be used. For data from the $20 \%$ damped acceleration response spectra (isolatedyielded periods) the following regression fits were obtained:

$\mathrm{T}_{I(\mathrm{UI})}=0.3 \mathrm{sec}$;

$$
\begin{gathered}
B_{D}=0.0368+0.0171\left(P_{2} / P_{1}\right)-0.0329\left(P_{1}\right), \\
\left(\bar{R}^{2}=.6625\right),
\end{gathered}
$$

$\mathrm{T}_{I(\mathrm{UI})}=0.6 \mathrm{sec}$

$$
\mathrm{B}_{\mathrm{D}}=0.2403+0.0251\left(\mathrm{P}_{2} / \mathrm{P}_{1}\right)-0.0862\left(\mathrm{P}_{1}\right) \text {, }
$$$$
\left(\overline{\mathrm{R}}^{2}=.6743\right) \text {, }
$$

$\mathrm{T}_{1(\mathrm{UI})}=0.9 \mathrm{sec} ;$

$$
\begin{aligned}
B_{D}=0.2574+0.0382\left(P_{2} / P_{1}-0.0541\left(P_{1}\right),\right. \\
\left(\bar{R}^{2}=.7422\right) .
\end{aligned}
$$

The residual plastic offset, $\delta_{\mathrm{PL}}$, in the isolation system following an earthquake showed no correlation with either $\mathrm{P}_{2} / \mathrm{P}_{1}$, $\mathrm{P}_{1}$ or $\mathrm{P}_{2}$, nor was there any tendency for $\delta_{\mathrm{PL}}$ to depend on $\mathrm{T}_{I \text { (UI) }}$.

\section{CONCLUSIONS}

(i) The maximum shear force, $\mathrm{S}$, in an isolated structure forced by a given earthquake can be accurately predicted from data such as the Housner Spectral Intensity, which gives only a general indication of the energy of the earthquake. This is not the case with unisolated structures where the variation in $S$ at a given H.S.I. is almost eight times that for the same structure on a base isolation system. Furthermore, S for an isolated structure is closely correlated with the value at

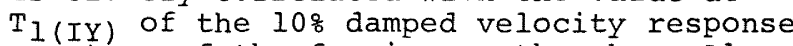
spectrum of the forcing earthquake. Almost equally good correlation was obtained when either the 5,10 or $20 \%$ damped velocity response spectra were used. Although $S$ for the unisolated structures displays better correlation with values of the 5\% damped acceleration response spectra at $\mathrm{T}_{1}(\mathrm{UT})$ than does the isolated response with any of the velocity response spectrum parameters, the actual widths of the $95 \%$ confidence intervals around the fitted lines for the isolated structures are of the order of one half of that for the unisolated structures, because of the much lower levels of $S$ in the isolated structures. Base isolation reduced the response of a given structure to a given earthquake to, on average, 0.2 of its value without base isolation.

(ii) For isolated structures there was in general a great improvement in the correlation between $B_{D}$ and earthquake parameters when the earthquake parameter took into account 
the structure 'periods'. The ratio of the value of the $20 \%$ damped acceleration response spectrum at $\mathrm{T}_{2}$ (IY) to the value of the same spectrum at $\mathrm{T}_{1}$ (IY) gave the best description of $\mathrm{B}_{\mathrm{D}}$ out of all the parameters investigated. There was a strong tendency for $B_{D}$ to decrease as $\mathrm{T}_{1}$ (UI) decreased. The values of $\mathrm{B}_{\mathrm{D}}$ for isolated structures of $\mathrm{T}_{\mathrm{I}}$ (UT) $=0.6$ and 0.9 seconds were not greatly diflerent from those of the same structures which were unisolated. However for structures of $\mathrm{T}_{1}(\mathrm{UI})=0.3$ seconds, base isolation greatly reduced the expected values of $\mathrm{BD}$. It is therefore low period structures that benefit most from base isolation, as not only is $\mathrm{S}$ greatly reduced but $\mathrm{B}_{\mathrm{D}}$ is reduced as well.

(iii) For the isolation system investigated here, the maximum base displacement was very closely correlated with $\mathrm{S}$, removing the necessity to treat it as a separate entity. The maximum base displacement was, of course, also strongly correlated with the same parameters as $S, e . g$. the value of the $10 \%$ damped velocity response spectrum at $\mathrm{T}_{1 \text { (IY) }}$

(iv) The residual plastic offset of the isolation system following an earthquake, displayed no correlation with any of the earthquake parameters investigated. For the entire set of structures and earthquakes considered, the residual offset had a mean value of $6 \mathrm{~mm}$, and a maximum value of $40 \mathrm{~mm}$. offsets of this order should present no great practical problems for the isolation system considered.

Hence, overall the Base Isolation System investigated reduced the shear forces in a structure subjected to strong earthquake forcing to a level of the order of one-fifth of the shears that would arise in the same structure without base isolation. For most strong earthquakes this means that the structure proper would be subjected to shears of less than 0.2 times the weight of the structure and a well-designed structure could resist such loads in a purely elastic response. Moreover it has been shown that there is a very close correlation between the forced response of isolated structures and selected values of the elastic response spectra of the forcing earthquake (e.g. the $10 \%$ damped velocity response spectrum at $T_{1}$ (IY)). These relationships have been quantified and confidence limits derived for estimates of structure response, using these relationships. If a structure is to be designed to resist a given 'design' earthquake then the results presented in this paper give a simple, one step method of accurately obtaining the design shear forces in the structure on the given base isolation system. Also if statistical information is avallable on the earthquake motions expected in a given region, then statistical limits can be placed on the expected response of a given structure on a given isolation system in that region, without having to perform an ensemble of inelastic forced vibration analyses. Such estimates can be made on the basis of a wide variety of data for the likely earthquake and will still yield close estimates of the structure responses.

\section{REFERENCES}

1. D. M. Lee, I. C. Medland, "Base Isolation - An Historical Review and the Influence of Higher Mode Responses", Bull. N.Z. Nat. Soc. Earthq. Eng., Vol. 11, No. 41978.
2. R. G. Tyler, "Dynamic Tests on Laminated Rubber Bearings", Bull. N.Z. Nat. Soc. Earthg. Engng, Vol. 10, No. 3, pp. 143150, (Sept. 1977).

3. R. I. Skinner, J. M. Kelly, A. J. Heine, "Hysteretic Dampers for Earthquake Resistant Structures", Int. J. Earthq. Engng Struct. Dyn., Vol. 3, pp. 287-296, (1975)

4. W. H. Robinson, L. R. Greenbank, "An Extrusion Energy Absorber Suitable for the Protection of Structures During an Earthquake", Int. J. Earthq. Engng Struct. Dyn., Vol. 4, pp. 251-259, (1976)

5. W. H. Robinson, A. G. Tucker, "A Lead Rubber Shear Damper", Bull. N.Z. Nat. Soc. Earthq. Engng, Vol. 10 No. 3, (September 1977).

6. R. I. Skinner, J. L. Beck, G. N. Bycroft, "A Practical System for Isolating Structures from Earthquake Attack", Int. J. Earthq. Engng Struct. Dyn., Vol. 3, pp. 297-309, (1975).

7. R. I. Skinner, G. H. McVerry, "Base Isolation for Increased Earthquake Resistance of Buildings", Bull. N.Z. Nat. Soc. Earthq. Engng, Vol. 8, No. 2, pp. 93-101, (1975).

8. R. I. Skinner, G. H. McVerry, "A Practical System for Isolating Nuclear Power Plants from Earthquake Attack" Nucl. Engng and Design, Vol. 36, No. 2, pp. 287-297, (1976)

9. A. K. Chopra, D. P. Clough, R. W. Clough, "Earthquake Resistance of Buildings with a Soft First Storey", Int. J. Earthq. Engng Struct. Dyn., Vol. 1, pp. 347-355, (1973).

10. M. J. N. Priestley, R. L. Crosbie, A. J. Carr, "Seismic Forces in Base Isolated Masonry Structures", Bull. N.Z. Nat. Soc. Earthq. Engng, Vol. 10, No. 2, pp. 56-68 (1977).

11. D. M. Lee, I. C. Medland, "Base Isolation for Earthquake Protection of Multistorey Shear Structures", Proc. 6th Aust. Confr. on Mech. and Structs of Mats, Vol. 1, pp. 181-188, (1977).

12. J. M. Kelly, J. M. Eidinger, C. J. Durham, "A Practical Soft Storey Earthquake Isolation System", Report No. UCB/EERC-77/27, Univ. of Calif., Berkeley (Nov. 1977).

13. D. M. Lee, "The Effect of Base Isolation of Multi-Storey Shear Structures", Ph.D. Thesis, Univ. of Auckland, Sch. of Engng, (July, 1978).

14. P.C. Jennings, G. W. Housner, N. C. Tsai, "Simulated Earthquake Motions", CALTECH, EERL, (April 1968).

15. "Strong Motion Earthquake Accelerograms - Digitized and Plotted Data", Vol. II, Corrected Accelerograms and Integrated Ground Velocity and Displacement Curves. Part A - ERRL 71-50 (Sept. 1971), Part B - EERL 72-50 (Feb. 1973), Part C - EERL 72-51 (Feb. 1973) Part D - EERL 72-52 (March 1973); CALTECH.

16. "Digitized Strong Motion Earthquake Accelerograms in Japan", Pub. Assoc. for Sci. Info. in Japan, (1972).

17. N. C. Nigam, P. C. Jennings, "Calculations of Response Spectra from Strong Motion Earthquake Records", Bull. Seism. Am. Vol. 59, No. 2, pp. 909-922, (April 1969).

18. H. B. Seed, C. Ugas, J. Lysmer, "Site Dependant Spectra for Earthquake Resistant Desiqn", Report No. UCB/EERC-74/12, Univ. of Calif., Berkeley, (November 1974). 


\begin{tabular}{|c|c|c|c|c|c|c|c|c|c|c|c|}
\hline Label & Earthquake & Date & Mag. & $\begin{array}{l}\text { Approx. } \\
\text { Source } \\
\text { Oist. } \\
(\mathrm{km})\end{array}$ & Dirn & $\begin{array}{l}\text { Max. } \\
\text { Acc. } \\
\text { (g) }\end{array}$ & $\begin{array}{l}\text { Max. } \\
\text { Yel. } \\
\left(\mathrm{m} / \mathrm{s}^{2}\right)\end{array}$ & $\begin{array}{l}\text { Soll } \\
\text { Depth }\end{array}$ & site & Site Type & $\begin{array}{l}\text { Source } \\
\text { of } \\
\text { Info. }\end{array}$ \\
\hline PNS & San Fernando & $9 / 2 / 71$ & 6.6 & 3 & S14W & 1.170 & 1.145 & Rock & Pacicina Dam & Rock & Ref.15 \\
\hline PEW & San Fernando & $9 / 2 / 71$ & 6.6 & 3 & N76 H & 1.075 & .594 & Rock & Pacioma Dam & Rock & - \\
\hline ELC & El Centro & $18 / 5 / 40$ & 6.6 & 8 & NS & 0.348 & .381 & 30 & El Centro & Stiff Soll & - \\
\hline P13 & Parkfield & $27 / 6 / 66$ & 5.6 & 0.1 & N65E & 0.489 & .760 & 48 & $\begin{array}{l}\text { Cholame Shandon } \\
\text { Stn.013 }\end{array}$ & Stiff Soil & " \\
\hline P14 & Parkfield & $27 / 6 / 66$ & 5.6 & 5 & N85E & 0.434 & .262 & 30 & $\begin{array}{l}\text { Cholame Shandon } \\
\text { Stn.014 }\end{array}$ & Stiff Soll & $"$ \\
\hline CNS & San Fernando & $9 / 2 / 17$ & 6.6 & 21 & N21E & 0.315 & .200 & 19 & $\begin{array}{l}\text { Castaic ald } \\
\text { Ridge Route }\end{array}$ & Stiff Soil & " \\
\hline CER & San Ferriando & $9 / 2 / 71$ & 6.6 & 21 & N69W & 0.270 & .338 & 19 & $\begin{array}{l}\text { Castaic Old } \\
\text { Ridge Route }\end{array}$ & Stiff Soll & " \\
\hline EUR & Eureka & $21 / 12 / 54$ & 6.5 & 25 & N79E & 0.257 & .299 & 80 & $\begin{array}{l}\text { Federal Bid. } \\
\text { - Eureka }\end{array}$ & Stiff Soll & " \\
\hline PUG & Puget Sound & $29 / 4 / 65$ & 6.5 & 58 & $586 \mathrm{~W}$ & 0.198 & .130 & 133 & $\begin{array}{l}\text { Hwy. Test Lab. } \\
\text { - Oiympia }\end{array}$ & Stiff Soll & " \\
\hline NNS & Niigata & $16 / 6 / 64$ & 7.7 & 70 & NS & 0.158 & 1.054 & & $\begin{array}{l}\text { Kawagishi-Cho } \\
\text { Apartment No.2 }\end{array}$ & Silt/Sand & Ref.16 \\
\hline NEW & Nígata & $16 / 6 / 64$ & 7.7 & 70 & EW & 0.162 & .811 & & $\begin{array}{l}\text { Kawagishi-Cho } \\
\text { Apartment No.2 }\end{array}$ & Silt/Sand & “ \\
\hline A1 & CALTECH A. & & $>8$ & Near Fault & & 0.384 & .596 & & $\begin{array}{l}\text { Simulated } \\
\text { Earthquake (Firm }\end{array}$ & Ground) & Ref.i4 \\
\hline A2 & CALTECH AZ & & $>8$ & Near Fault & & 0.450 & .551 & & $\begin{array}{l}\text { Simulated } \\
\text { Earthquake (Firm }\end{array}$ & Ground) & - \\
\hline$B 1$ & CALTECH BI & & $>7$ & & & 0.375 & .359 & & $\begin{array}{l}\text { Simulated } \\
\text { Earthquake (Firm }\end{array}$ & Ground) & $*$ \\
\hline 82 & CALTECH .E2 & & $>7$ & & & 0.315 & .479 & & $\begin{array}{l}\text { Simulated } \\
\text { Earthquake (Fim }\end{array}$ & Ground) & " \\
\hline C1 & CALTECH C1 & & $5.5-6.0$ & Epicentral & Region & 0.0683 & .0694 & & $\begin{array}{l}\text { Simulated } \\
\text { Earthquake (Finm }\end{array}$ & Ground) & - \\
\hline $\mathrm{C2}$ & CALTECH C2 & & $5.6-6.0$ & Epicentral & Region & 0.0584 & .0600 & & $\begin{array}{l}\text { Simulated } \\
\text { Earthquake (Firm }\end{array}$ & Ground) & " \\
\hline DI & CALTECH D 1 & & & $\begin{array}{l}\text { Near Fault } \\
\text { shallow Eq. }\end{array}$ & & 0.485 & .274 & & $\begin{array}{l}\text { Simulated } \\
\text { Earthquake (Firm }\end{array}$ & Ground) & " \\
\hline D2 & CALTECH D2 & & & $\begin{array}{l}\text { Near Fault } \\
\text { Shallo'n Eq. }\end{array}$ & & 0.492 & .294 & & $\begin{array}{l}\text { Simulated } \\
\text { Earthquake (Firm }\end{array}$ & Ground & . \\
\hline
\end{tabular}

TABLE 1: EARTHQUAKE RECORDS USED IN THE ANALYSIS.

\begin{tabular}{|c|c|c|c|c|c|c|c|}
\hline \multirow{2}{*}{$\begin{array}{l}\text { Parameter } \\
\text { Number }\end{array}$} & \multirow{2}{*}{$\begin{array}{l}\text { Parameter } \\
\text { Name }\end{array}$} & \multicolumn{3}{|c|}{ Isolated Structures } & \multicolumn{3}{|c|}{ Unisolated Structures } \\
\hline & & $\bar{R}^{2}$ & $\begin{array}{l}\text { Slope } \\
\text { (b) }\end{array}$ & $\begin{array}{l}\text { Intercept } \\
\text { (a) }\end{array}$ & $R^{-2}$ & $\begin{array}{l}\text { Slope } \\
\text { (b) }\end{array}$ & $\begin{array}{l}\text { Intercept } \\
\text { (a) }\end{array}$ \\
\hline 1 & M.G.V. & .738 & .2433 & .0339 & .120 & .4807 & .3374 \\
\hline 2 & M.G.A. & .398 & .0196 & .0686 & .464 & .0976 & .1779 \\
\hline 3 & H.S.I. $20 \%$ & .814 & .1353 & .0187 & .488 & .4873 & .1024 \\
\hline 4 & H.S.I. 10\% & .839 & .1079 & .0164 & .489 & .3834 & .1001 \\
\hline 5 & H.S.I. $5 \%$ & .839 & .0879 & .0163 & .488 & .3123 & .1000 \\
\hline 6 & M.S.A. $20 \%$ & .401 & .0147 & .0564 & .506 & .0760 & .1000 \\
\hline 7 & M.S.A.10 & .393 & .0110 & .0574 & .506 & .0574 & .1005 \\
\hline 8 & M.S.A. $5 \%$ & .428 & .0084 & .0554 & .499 & .0418 & .1117 \\
\hline 9 & M.S.V. $20 \%$ & .907 & .2407 & .0075 & .358 & .7087 & .1522 \\
\hline 10 & M.S.V. $10 \%$ & .847 & .1702 & .0140 & .417 & .5577 & .1278 \\
\hline 11 & M.S.V. $5 \%$ & .771 & .1262 & .0192 & .465 & .4564 & .1022 \\
\hline
\end{tabular}




\begin{tabular}{|c|c|c|c|c|c|c|c|c|c|c|}
\hline \multirow{2}{*}{$\begin{array}{l}T_{1(U I)} \\
(\mathrm{sec})\end{array}$} & \multirow{2}{*}{\multicolumn{2}{|c|}{$\frac{\text { Unt solated }}{\mathrm{T}_{2(\mathrm{UI})}}$}} & \multicolumn{4}{|c|}{ Isolated Unyielded } & \multicolumn{4}{|c|}{ Isolated Yielded } \\
\hline & & & ${ }_{1}^{T_{1}}$ & IUY) & $\mathrm{T}_{2}$ & IUY) & ${ }_{1}^{T_{1}}$ & IY) & & IY) \\
\hline 0.3 & .1020 & .10 & 1.004 & 1.00 & .1583 & .15 & 2.183 & 2.20 & .1616 & .15 \\
\hline 0.6 & .2039 & .20 & 1.110 & 1.10 & .2952 & .30 & 2.230 & 2.25 & .3182 & .30 \\
\hline 0.9 & .3059 & .30 & 1.278 & 1.30 & .4052 & .40 & 2.309 & 2.30 & .4656 & .45 \\
\hline
\end{tabular}

TABLE 3: ACTUAL AND APPROXIMATE FIRST AND SECOND MODE PERIODS (AND PSEUDO PERIODS) FOR THE STRUCTURES CONSIDERED.

\begin{tabular}{|c|c|c|c|c|c|c|c|c|}
\hline \multirow{2}{*}{$\begin{array}{l}\text { Spectrum } \\
\text { Dainping } \\
\text { Used }\end{array}$} & \multirow{2}{*}{$\begin{array}{c}\text { Structure } \\
\text { Type }\end{array}$} & \multirow{2}{*}{$\begin{array}{l}\text { Approximate } \\
\text { Structure } \\
\text { Periods Used }\end{array}$} & \multicolumn{3}{|c|}{$\begin{array}{l}\text { Acceleration Sjectra Data } \\
\bar{R}^{2} \text { using Parameters, }\end{array}$} & \multicolumn{3}{|c|}{$\frac{\text { Velocity Spectra Data }}{\bar{R}^{2} \text { using Parameters, }}$} \\
\hline & & & $P_{1}+P_{2}$ & $P_{1}$ & $P_{2}$ & $P_{1}+P_{2}$ & $P_{1}$ & $P_{2}$ \\
\hline \multirow{2}{*}{$5 \%$} & Unisol. & UI & .9868 & .9869 & .2506 & .8430 & .6791 & -.0054 \\
\hline & Isol. & $\begin{array}{l}\text { IUY } \\
\text { IY }\end{array}$ & $\begin{array}{l}.6843 \\
.8733\end{array}$ & $\begin{array}{l}.6860 \\
.8201\end{array}$ & $\begin{array}{l}.3351 \\
.3356\end{array}$ & $\begin{array}{l}.6789 \\
.9240\end{array}$ & $\begin{array}{l}.6672 \\
.9247\end{array}$ & $\begin{array}{l}.1882 \\
.1866\end{array}$ \\
\hline \multirow[b]{2}{*}{$10 \%$} & Unisol. & UI & .9624 & .9624 & .1504 & .5310 & .3320 & .0027 \\
\hline & Isol. & $\begin{array}{l}\text { IUY } \\
\text { IY }\end{array}$ & $\begin{array}{l}.7258 \\
.9138\end{array}$ & $\begin{array}{l}.7143 \\
.8792\end{array}$ & $\begin{array}{l}.3270 \\
.3175\end{array}$ & $\begin{array}{l}.7002 \\
.9477\end{array}$ & $\begin{array}{l}.6711 \\
.9485\end{array}$ & $\begin{array}{l}.1732 \\
.1670\end{array}$ \\
\hline \multirow[b]{2}{*}{$20 \%$} & Unisol. & UI & .9423 & .9327 & .4261 & .5051 & .2695 & .0365 \\
\hline & Isol. & $\begin{array}{l}\text { IUY } \\
\text { IY }\end{array}$ & $\begin{array}{l}.8006 \\
.9447\end{array}$ & $\begin{array}{l}.7640 \\
.9386\end{array}$ & $\begin{array}{l}.3389 \\
.3264\end{array}$ & $\begin{array}{l}.7367 \\
.9339\end{array}$ & $\begin{array}{l}.6788 \\
.9324\end{array}$ & $\begin{array}{l}.1724 \\
.1682\end{array}$ \\
\hline
\end{tabular}

TABLE 4: SUMMARY OF THE DEGREE OF CORRELATION BETWEEN S (FOR ISOLATED AND UNISOLATED STRUCTURES) AND PARAMETERS $P_{1}$ AND $P_{2}$ TOGETHER, $\mathrm{P}_{1}$ ALONE AND $\mathrm{P}_{2}$ ALONE.

\begin{tabular}{|c|c|c|c|c|c|c|}
\hline \multicolumn{3}{|c|}{ Structure and Parameter Data } & \multicolumn{4}{|c|}{ Regression Line Data } \\
\hline $\begin{array}{c}\text { Structure } \\
\text { Type }\end{array}$ & $\begin{array}{l}\text { Structure } \\
\text { Period Used }\end{array}$ & $\begin{array}{c}\text { Response } \\
\text { Spectrum Used }\end{array}$ & $\begin{array}{l}\bar{R}^{2} \text { for fit } \\
\text { of } S \text { to } P_{1}\end{array}$ & $\begin{array}{l}\text { Slope of } \\
\text { Regression Line }\end{array}$ & $\begin{array}{l}\text { Intercept of } \\
\text { Regression Line }\end{array}$ & $\begin{array}{ll}\text { Approx. } & 95 \% \\
\text { Confid. Ints. }\end{array}$ \\
\hline Unisol. & $T_{1}(U I)$ & Acc. $(5 \approx d)$ & .9869 & .0893 & .0103 & \pm .094 \\
\hline \multirow{5}{*}{ Isol. } & \multirow{5}{*}{$T_{1(I V)}$} & Vel. (20 d) & .9324 & & .0156 & \pm .046 \\
\hline & & Vel. (10\%d) & .9485 & .2355 & .0106 & \pm .041 \\
\hline & & Vel. ( $5 \% d$ ) & .9247 & .2024 & .0106 & \pm .049 \\
\hline & & Acc. $(20 \% d)$ & .9386 & .1070 & .0176 & \pm .044 \\
\hline & & Acc. $(5 \pi d)$ & .8201 & .0713 & .0275 & \pm .076 \\
\hline
\end{tabular}

TABLE 5: LINEAR LEAST SOUARES REGRESSION FITS OF S TO SELECTED SPECTRAL PARAMETERS. 


\begin{tabular}{|c|c|c|c|c|c|c|c|c|}
\hline \multirow{2}{*}{$\begin{array}{l}\text { Spectrum } \\
\text { Damping }\end{array}$} & \multirow{2}{*}{$\begin{array}{l}\text { System } \\
\text { Periods } \\
\text { Used }\end{array}$} & \multirow{2}{*}{$\begin{array}{l}T_{1}(U I) \\
(\mathrm{sec})\end{array}$} & \multicolumn{3}{|c|}{$\frac{\text { Acceleration Spectra Data }}{\bar{R}^{2} \text { for }}$} & \multicolumn{3}{|c|}{$\frac{\text { Velocity Spectra Data }}{\bar{R}^{2} \text { for }}$} \\
\hline & & & $P_{2} / P_{1}+P_{1}$ & $P_{2} / P_{1}$ & $P_{1}$ & $P_{2} / P_{1}+P_{1}$ & $P_{2} / P_{1}$ & $P_{1}$ \\
\hline \multirow{9}{*}{$5 \%$} & \multirow{3}{*}{ UI } & .3 & -.0715 & -.0253 & -.0346 & -.0577 & -.0420 & -.0197 \\
\hline & & .6 & .4521 & .4824 & .0039 & .3082 & .3389 & -.0400 \\
\hline & & .9 & .5078 & .5366 & -.0309 & .5304 & .5577 & -.0423 \\
\hline & \multirow{3}{*}{ IUY } & .3 & .6029 & .5709 & .2063 & .5288 & .4782 & .1693 \\
\hline & & .6 & .3564 & .3462 & .1351 & .3012 & .2848 & .1095 \\
\hline & & .9 & .4052 & .3964 & .1405 & .4779 & .4804 & .1039 \\
\hline & \multirow{3}{*}{ IY } & .3 & .3686 & .2054 & .3873 & .3038 & .1831 & .2963 \\
\hline & & .6 & .6942 & .4977 & .6071 & .7168 & .5721 & .5090 \\
\hline & & .9 & .5087 & .3163 & .5017 & .4849 & .3745 & .3740 \\
\hline \multirow{9}{*}{$10 \%$} & \multirow{3}{*}{ UI } & .3 & -.1133 & -.0536 & -.0479 & -.1089 & -.0587 & -.0446 \\
\hline & & .6 & .4301 & .4557 & -.0302 & .2803 & .2950 & -.0571 \\
\hline & & .9 & .6074 & .6279 & -.0239 & .6318 & .6534 & -.0393 \\
\hline & \multirow{3}{*}{ IUY } & .3 & .6638 & .6242 & .1836 & .5951 & .5197 & .1577 \\
\hline & & .6 & .4289 & .4222 & .1427 & .4043 & .4059 & .0804 \\
\hline & & .9 & .4354 & .4364 & .1122 & .5067 & .5152 & .0770 \\
\hline & \multirow{3}{*}{ IY } & .3 & .4474 & .3514 & .4026 & .3969 & .3072 & .2976 \\
\hline & & .6 & .7667 & -.0228 & .5894 & .7034 & .6009 & .4449 \\
\hline & & .9 & .5728 & .4277 & .5101 & .6086 & .5132 & .3358 \\
\hline \multirow{9}{*}{$20 \%$} & \multirow{3}{*}{ UI } & .3 & -.1082 & -.0430 & -.0581 & -.1064 & -.0495 & -.0530 \\
\hline & & .6 & .3249 & .3616 & -.0523 & .2542 & .2718 & -.0577 \\
\hline & & .9 & .6099 & .6306 & -.0238 & .4736 & .5029 & -.0539 \\
\hline & \multirow{3}{*}{ IUY } & .3 & .7840 & .7346 & .1878 & .6804 & .5680 & .1474 \\
\hline & & .6 & .4927 & .4637 & .1671 & .4628 & .4447 & .0817 \\
\hline & & .9 & .5654 & .5704 & .1115 & .5754 & .5829 & .0540 \\
\hline & \multirow{3}{*}{ IY } & .3 & .6625 & .6226 & .4161 & .5813 & .5289 & .2811 \\
\hline & & .6 & .6743 & .5713 & .5216 & .6610 & .5707 & .3750 \\
\hline & & .9 & .7422 & .6980 & .4568 & .7100 & .6504 & .2528 \\
\hline
\end{tabular}

TABLE 6: $R_{2}$ FOR THE LEAST SQUARES REGRESSION FITS OF $B_{D}$ AGAINST $P_{2} / P_{1}$ AND $P_{1}$ FOR ISOLATED AND UNISOLATED STRUCTURES. 
$S$

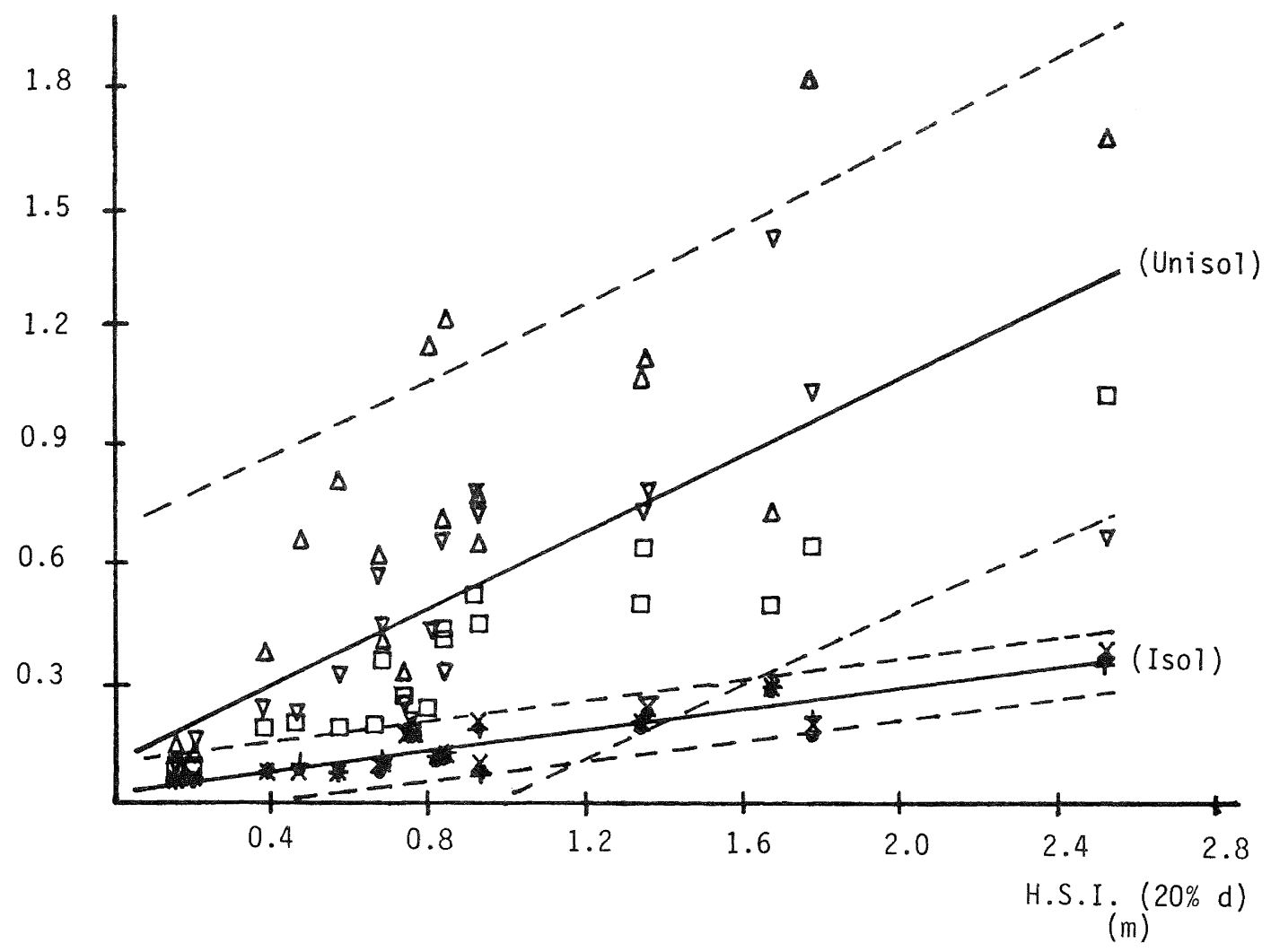

FIGURE 1: S VERSUS THE 20\% DAMPED HOUSNER SPECTRAL INTENSITY OF THE FORCING EARTHOUAKE; FOR ISOLATED AND UNISOLATED STRUCTURE.

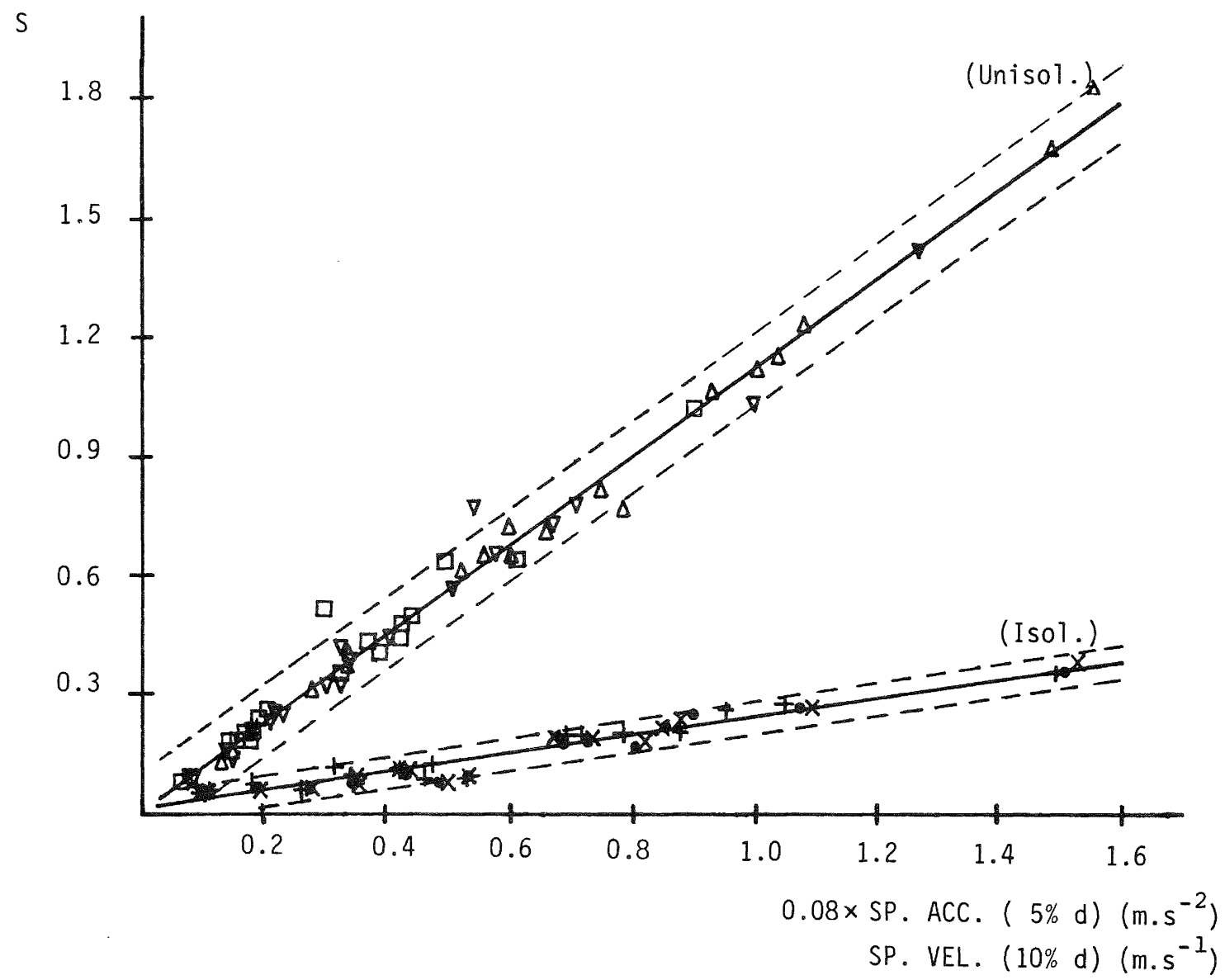

FIGURE 2: S FOR UNISOLATED STRUCTURES VERSUS THE 5\% DAMPED SPECTRAL ACCELERATION AT T 1 (UI), AND S FOR ISOLATED STRUCTURES VERSUS THE 10\% DAMPED SPECTRAL VELOCITY AT T $1(I Y)$. 
$B_{D}$

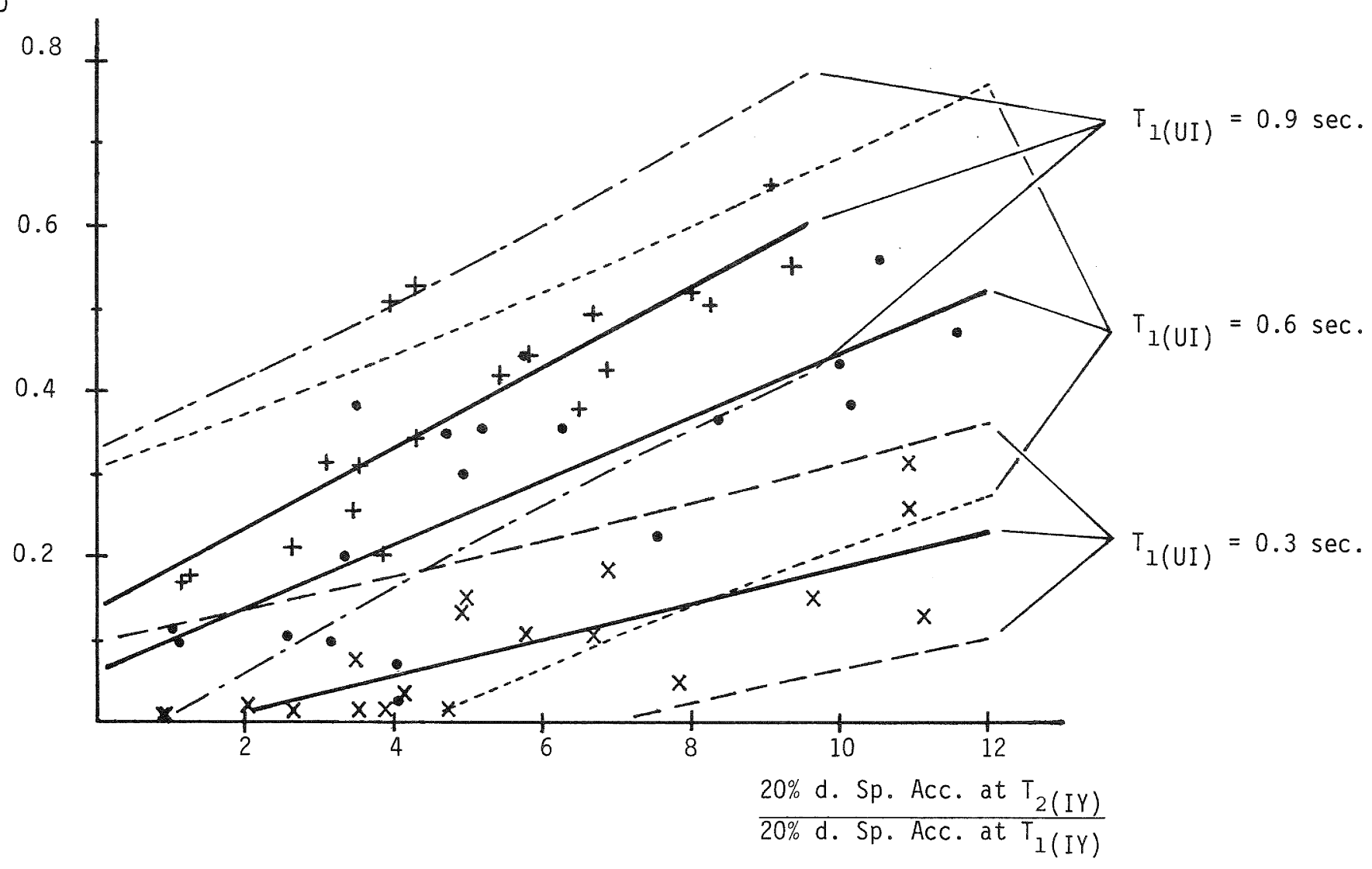

FIGURE 3: $B_{D}$ FOR ISOLATED STRUCTURES VERSUS $P_{2} / P_{1}$ FROM THE 20\% DAMPED ACCELERATION RESPONSE SPECTRA OF THE FORCING EARTHQUAKE.

$B_{D}$

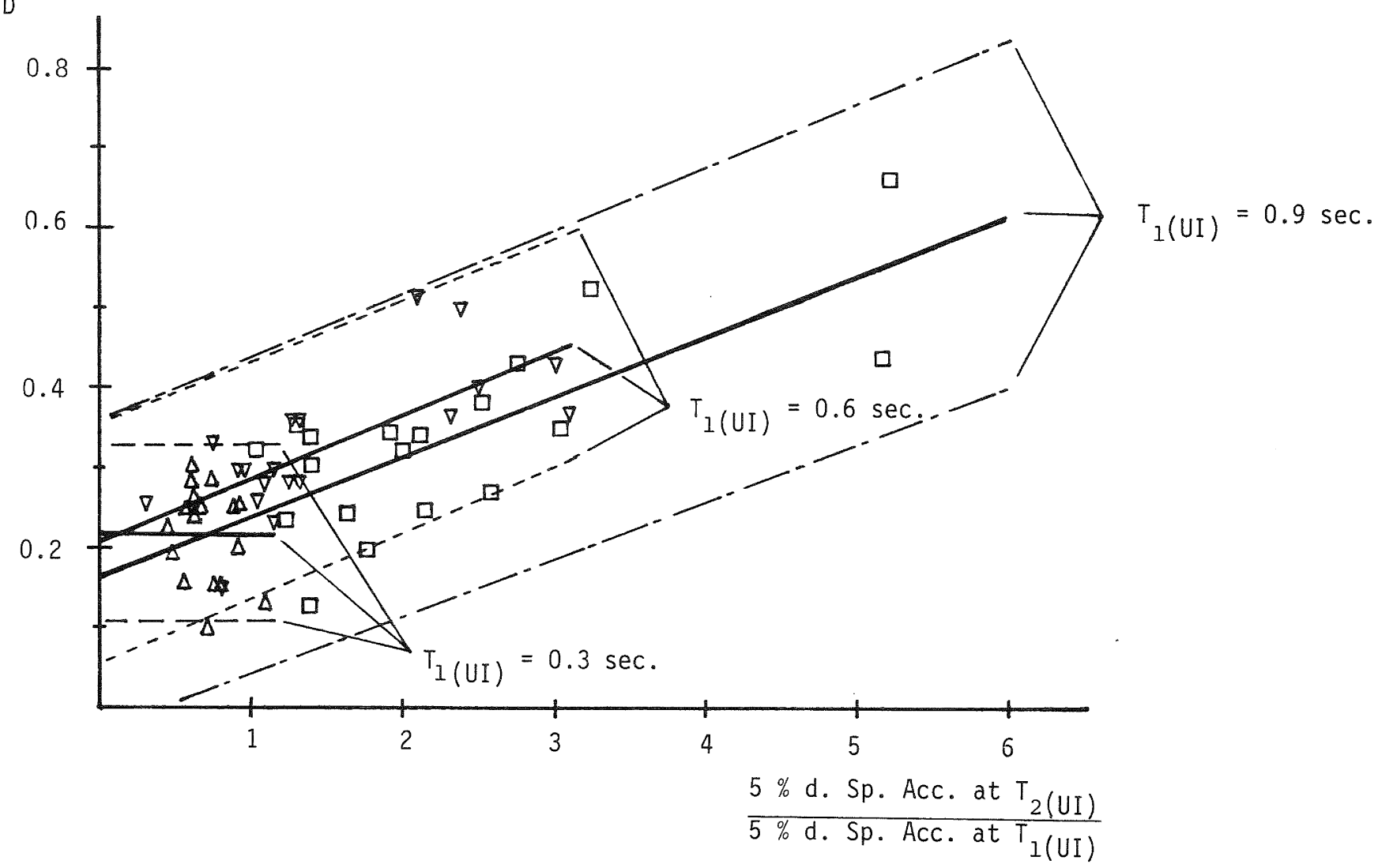

FIGURE 4: $B_{D}$ FOR UNISOLATED STRUCTURES VERSUS $P_{2} / P_{1}$ FROM THE 5\% DAMPED ACCELERATION RESPONSE SPECTRA OF THE FORCING EARTHOUAKE. 